\title{
Comparative Study of the Spillover Effects of Hong Kong and Macau's Educational Investment on Regional Economic Growth Based on the Feder Model
}

\author{
Lin $\mathrm{XU}^{1,2}$, Jun $\mathrm{ZHU}^{1}$ and Yan LIU \\ ${ }^{1}$ Macau University of Science and Technology, Macau 999078, China \\ ${ }^{2}$ Beijing Normal University Zhuhai Campus, Zhuhai 519085, China
}

Keywords: Educational investment, Economic growth, Spillover effect, Feder model.

\begin{abstract}
In this paper, we use Feder model to compare the contribution of education investment to economic growth and spillover effects in Hong Kong and Macau Special Administrative Region in the past 2002-2015 years. The study shows that the educational input of the two places has an obvious boost to economic growth, but it has a difference in time. At the same time, the contribution of education in Macau is greater than that of Hong Kong; the educational input of the two places is more effective for the non education sector, and Hong Kong is effective for a long time, while Macau only has the short term spillover effect and the long term is negative. The efficiency of education departments in both places is lower than that in non education sectors. In this regard, this paper suggests that the government of Macau should optimize and upgrade its industrial transformation and study abroad policy.
\end{abstract}

\section{Introduction}

Hong Kong and Macau are two special administrative regions in China, how are their educational investment efficiency and effectiveness? Are there any obvious differences? Through empirical research on the contribution and spillover effect of education investment to economic growth in Hong Kong and Macau, the problems and differences between them are analyzed and compared, and the policy proposals to promote economic growth are finally put forward. It is of great practical significance.

As Hongkong and Macau as two special administrative regions in China, how are their educational investment efficiency and effectiveness? Are there any obvious differences? Through empirical research on the contribution and spillover effect of education investment to economic growth in Hong Kong and Macau, the problems and differences between them are analyzed and compared, and the policy proposals to promote economic growth are finally put forward. It is of great practical significance.

\section{Literature Review}

Schultz (1961) uses growth balance analysis to study educational investment and economic growth. Dension (1962) uses growth accounting method to decompose each factor that affects economic growth one by one, and calculates the contribution rate of education input to economic growth. Romer (1986) explain the mechanism of education promoting economic growth based on endogenous economic growth theory. Since 1990s, some domestic scholars have used Cobb Douglas production function regression analysis to study the relationship between educational investment and economic growth, and the conclusions of the study are positive. Inspired by the Feder model, Yao Yilong (2011) compare the spillover effects of education between China and the United States. The results show that the total contribution of Chinese education investment to economic growth is greater than that of the United States, and the productive efficiency of the educational departments of both countries is lower than that of the non educational sector. A comparative study based on the data of Beijing, Shanghai and Guangdong Based on the 1996-2012 years of Beijing, Shanghai and Guangdong (2014) has been made to find that the educational input 
in the lower level of educational development has a more significant, positive and lasting growth driving force. The literature review shows that the research on the contribution of education investment to economic growth is relatively more, but the literature on the contribution of educational input to economic growth in Hong Kong and Macau is rare, and the comparative study of the contribution and spillover effect of the investment in Hong Kong and Macau to the economic growth is almost blank with the Feder model.

\section{Model Construction and Sample Selection}

Model Construction. Based on the principle of Feder model, this paper assumes that the social sector is divided into two departments: the education department and the non education department.

$$
\begin{aligned}
& E=f\left(L_{\mathrm{e}}, K_{\mathrm{e}}\right) \\
& N=g\left(L_{n}, K_{n}, E\right)
\end{aligned}
$$

In the above formula, $E$ and $N$ represent the output of the education sector and the non education sector respectively, $L$ and $K$ represent labor and capital input respectively.

The expressions of $L$ (labor force), $K$ (capital input) and $Y$ (local residents' economic) are:

$$
\begin{aligned}
& L=L_{e}+L_{n} \\
& K=K_{e}+K_{n} \\
& Y=E+N
\end{aligned}
$$

The Feder model illustrates the relationship between the marginal output of labor force and capital input in different sectors:

$$
\frac{f_{L}}{g_{L}}=\frac{f_{K}}{f_{K}}=1+\delta
$$

In the following formulas, $f_{L}, f_{K}, g_{L}, g_{K}$ represents the marginal output of labor and capital input: $f_{L}=\frac{\partial E}{\partial L_{e}}, f_{K}=\frac{\partial E}{\partial K_{e}}, g_{L}=\frac{\partial N}{\partial L_{n}}, g_{K}=\frac{\partial N}{\partial K_{n}}, \delta$ represents the relative marginal productivity difference between the education sector and the non education sector. The formula(5) is two times differential and combined with (2), (3), (4) and (6) the following formula can be obtained:

$$
\frac{d Y}{Y}=\alpha_{a}\left(\frac{K}{Y}\right)+\beta_{a}\left(\frac{d L}{L}\right)+\gamma\left(\frac{d E}{E}\right)\left(\frac{E}{Y}\right)
$$

In formula(7), $\gamma$ indicates the total impact of educational sector input on economic growth. In order to further estimate the spillover effect of educational products, it is assumed that the elasticity of products in non educational sectors is constant.

$$
N=g\left(L_{n}, K_{n}, E\right)=E_{\phi}^{\theta}\left(L_{n}, K_{n}\right)
$$

In formula(8), $\theta$ represents the spillover effect and can continue to find out:

$$
g_{E}=\frac{\delta N}{\delta E}=\theta\left(\frac{N}{E}\right)
$$

$g_{E}$ is the marginal contribution of the educational department to the non educational sector, By using (8) and (9), the transformation of (7) is as follows:

$$
\frac{d Y}{Y}=\alpha_{b}\left(\frac{K}{Y}\right)+\beta_{b}\left(\frac{d L}{L}\right)+\left[\frac{\delta}{1+\delta}+\theta\left(\frac{N}{E}\right)\right]\left(\frac{d E}{E}\right)\left(\frac{E}{Y}\right)
$$


After the adjustment can be obtained:

$$
\frac{d Y}{Y}=\alpha_{b}\left(\frac{K}{Y}\right)+\beta_{b}\left(\frac{d L}{L}\right)+\left(\frac{\delta}{1+\delta}-\theta\right)\left(\frac{d E}{E}\right)\left(\frac{E}{Y}\right)+\theta\left(\frac{d E}{E}\right)
$$

Since there is no statistical item about $K$ ( Capital increment ) in all kinds of statistical yearbooks, we can draw on the thought of Xiao Lu, Ming Fan (2008) and replace it with investment, so we can get the following two model formulas:

$$
\begin{aligned}
& \frac{d Y}{Y}=\alpha_{a}\left(\frac{I}{Y}\right)+\beta_{a}\left(\frac{d L}{L}\right)+\gamma\left(\frac{d E}{E}\right)\left(\frac{E}{Y}\right) \\
& \frac{d Y}{Y}=\alpha_{b}\left(\frac{I}{Y}\right)+\beta_{b}\left(\frac{d L}{L}\right)+\left(\frac{\delta}{1+\delta}-\theta\right)\left(\frac{d E}{E}\right)\left(\frac{E}{Y}\right)+\theta\left(\frac{d E}{E}\right)
\end{aligned}
$$

In formula(12), $\alpha$ represents the marginal output of the capital input from the non educational sector, $\beta$ represents the elasticity of the non educational sector's products to the labor force, $\gamma$ represents the full role of education for economic growth, $d Y / Y 、 d L / L$ and $d E / E$ represent the growth rate of the economy, the growth rate of the labor force and the growth rate of education input, $I / Y$ represents the percentage of the investment in the GDP. The proportion of educational output to total social output is shown by $E / Y$. In formula(13), The spillover effect of the education sector represented by $\theta, \frac{\delta}{1+\delta}-\theta$ represents the marginal productivity difference between the educational sector and the non education sector.

Considering that the output of education includes long term products such as knowledge and talents, it also includes short-term consumption of school students. Therefore, this paper introduces the front of educational input to illustrate the short-term and long-term effects of educational output respectively.

$$
\begin{aligned}
\frac{d Y}{Y} & =c_{I}+\alpha_{I}\left(\frac{I}{Y}\right)+\beta_{I}\left(\frac{d L}{L}\right)+\gamma_{I}\left(\frac{d E}{E}\right)\left(\frac{E}{Y}\right)+\rho_{I}\left(\frac{d E}{E}\right)\left(\frac{E}{Y}\right)_{t-1}+\tau_{I}\left(\frac{d E}{E}\right)\left(\frac{E}{Y}\right)_{t-2}+\mu_{I} \\
\frac{d Y}{Y} & =c_{I I}+\alpha_{I I}\left(\frac{I}{Y}\right)+\beta_{I I}\left(\frac{d L}{L}\right)+\varphi_{I I}\left(\frac{d E}{E}\right)\left(\frac{E}{Y}\right)_{t-4}+\mu_{I I} \\
\frac{d Y}{Y} & =c_{I I I}+\alpha_{I I I}\left(\frac{I}{Y}\right)+\beta_{I I I}\left(\frac{d L}{L}\right)+\gamma_{I I I}\left(\frac{d E}{E}\right)\left(\frac{E}{Y}\right)+\rho_{I I I}\left(\frac{d E}{E}\right)\left(\frac{E}{Y}\right)_{t-1} \\
& +\tau_{I I I}\left(\frac{d E}{E}\right)\left(\frac{E}{Y}\right)_{t-2}+\theta_{I I I}\left(\frac{d E}{E}\right)+\mu_{I I I} \\
\frac{d Y}{Y} & =c_{I V}+\alpha_{I V}\left(\frac{I}{Y}\right)+\beta_{I V}\left(\frac{d L}{L}\right)+\gamma_{I V}\left(\frac{d E}{E}\right)\left(\frac{E}{Y}\right)+\theta_{I V}\left(\frac{d E}{E}\right)_{t-4}+\mu_{I V}
\end{aligned}
$$

In order to examine the difference between the educational sector and the non education sector, the estimated parameter is $\delta$. It is known by the formula(13), in formula(III)and (IV), $\gamma=\frac{\delta}{1+\delta}-\theta$. formula (I) and (III) indicate the short-term effects of educational input, $\mathrm{t}=0,-1,-2$; formula(II) and (IV) indicate the long-term effects of educational input, $\mathrm{t}=4$.

Sample Selection. This paper selects economic samples from Hong Kong and Macau from 2002 to 2015. The economic growth $(Y)$ variable adopts the GDP of Hong Kong and Macau in the same year. The labor force $(L)$ adopts the total number of employment labor in Hong Kong and Macau. Investment $(I)$ is direct investment, and education investment $(E)$ is invested in public education. 


\section{Empirical Results Analysis}

In this paper, the WLS is used to estimate the formula(I), (II), (III) and (IV), in which the weight is $w=1 /$ abs(resid), and the regression results are shown as shown in Table 1.

Table 1. Regression results of Feder model

\begin{tabular}{|c|c|c|c|c|c|c|c|c|c|c|}
\hline \multicolumn{3}{|c|}{ Model } & \multicolumn{2}{|c|}{ (I) } & \multicolumn{2}{|c|}{ (II) } & \multicolumn{2}{|c|}{ (III) } & \multicolumn{2}{|c|}{ (IV) } \\
\hline Variable & $\begin{array}{c}\text { Coefficie } \\
\text { nt }\end{array}$ & $\begin{array}{l}\text { Regio } \\
\text { n }\end{array}$ & $\begin{array}{c}\text { Coeffic } \\
\text { ient }\end{array}$ & Prob & $\begin{array}{c}\text { Coeffic } \\
\text { ient }\end{array}$ & Prob & $\begin{array}{c}\text { Coeffic } \\
\text { ient }\end{array}$ & Prob & $\begin{array}{c}\text { Coeffic } \\
\text { ient }\end{array}$ & Prob \\
\hline \multirow{2}{*}{\multicolumn{2}{|c|}{$C$}} & HK & -0.09 & 0.007 & -0.36 & 0.000 & -0.19 & 0.013 & -0.55 & 0.001 \\
\hline & & Macau & 0.33 & 0.001 & 0.93 & 0.000 & 0.30 & 0.002 & 0.92 & 0.000 \\
\hline$I$ & \multirow[b]{2}{*}{$\alpha$} & HK & 0.27 & 0.001 & 0.73 & 0.000 & 0.50 & 0.009 & 1.18 & 0.000 \\
\hline$\frac{1}{Y}$ & & Macau & -0.80 & 0.000 & -1.58 & 0.000 & -0.63 & 0.001 & -1.61 & 0.000 \\
\hline \multirow{2}{*}{$\frac{d L}{L}$} & \multirow[b]{2}{*}{$\beta$} & $\mathrm{HK}$ & 2.08 & 0.013 & 1.04 & 0.000 & 2.34 & 0.000 & 1.39 & 0.015 \\
\hline & & Macau & 1.27 & 0.000 & 0.85 & 0.008 & 0.41 & 0.260 & 0.98 & 0.003 \\
\hline \multirow{2}{*}{$\left(\frac{d E}{E}\right)\left(\frac{E}{Y}\right)$} & \multirow[b]{2}{*}{$\gamma$} & HK & -9.63 & 0.3478 & & & 608.02 & 0.040 & -34.39 & 0.001 \\
\hline & & Macau & 7.76 & 0.001 & & & -62.47 & 0.014 & -1.27 & 0.022 \\
\hline \multirow{2}{*}{$\left(\frac{d E}{E}\right)\left(\frac{E}{Y}\right)_{t-1}$} & \multirow[b]{2}{*}{$\rho$} & HK & -13.39 & 0.027 & & & -28.71 & 0.003 & & \\
\hline & & Macau & 11.06 & 0.001 & & & 18.47 & 0.001 & & \\
\hline \multirow{2}{*}{$\left(\frac{d E}{E}\right)\left(\frac{E}{Y}\right)_{t-2}$} & \multirow[b]{2}{*}{$\tau$} & HK & 7.32 & 0.041 & & & 1.11 & 0.738 & & \\
\hline & & Macau & 12.48 & 0.000 & & & 18.07 & 0.001 & & \\
\hline \multirow{2}{*}{$\left(\frac{d E}{E}\right)\left(\frac{E}{Y}\right)_{t-4}$} & \multirow[b]{2}{*}{$\varphi$} & $\mathrm{HK}$ & & & 7.28 & 0.009 & & & & \\
\hline & & Macau & & & -21.20 & 0.030 & & & & \\
\hline \multirow{2}{*}{$\frac{d E}{E}$} & \multirow{2}{*}{$\theta_{I I I}$} & $\mathrm{HK}$ & & & & & -18.21 & 0.040 & & \\
\hline & & Macau & & & & & 1.64 & 0.009 & & \\
\hline \multirow{2}{*}{$\left(\frac{d E}{E}\right)_{t-4}$} & \multirow[b]{2}{*}{$\theta_{I V}$} & HK & & & & & & & 0.38 & 0.001 \\
\hline & & Macau & & & & & & & -0.47 & 0.003 \\
\hline \multirow{2}{*}{\multicolumn{2}{|c|}{$\delta$}} & $\mathrm{HK}$ & & & & & \multicolumn{2}{|c|}{-1.00} & \multicolumn{2}{|c|}{-0.97} \\
\hline & & Macau & & & & & \multirow{2}{*}{\multicolumn{2}{|c|}{$\begin{array}{c}-0.90 \\
0.9860\end{array}$}} & \multirow{2}{*}{\multicolumn{2}{|c|}{$\frac{-0.64}{0.9826}$}} \\
\hline \multirow{2}{*}{\multicolumn{2}{|c|}{ R-squared }} & HK & \multicolumn{2}{|c|}{0.9863} & 0.9 & & & & & \\
\hline & & Macau & \multirow{2}{*}{\multicolumn{2}{|c|}{$\frac{0.9852}{0.0001}$}} & 0.9 & & \multicolumn{2}{|c|}{0.9981} & & \\
\hline Proho & & $\mathrm{HK}$ & & & 0.0 & & 0.0 & & & \\
\hline $\operatorname{Prob}(F$ & tistic) & Macau & & & 0.0 & & 0.0 & & & \\
\hline
\end{tabular}

The regression results of formula (I) show that Hong Kong is not significant, but Macau is all significant, indicating that education input has no effect on Hong Kong's short-term economic growth, but it has a significant impact on Macau. The regression results of formula (II) show that Hong Kong is not significant and Macau is not significant, indicating that the investment in Macau's education has not promoted the economic development in the long run. The regression results of the formula (III) showed that Hong Kong was not significant, while Macau was significant, indicating that the education input in Hong Kong had no spillover effect on the non educational sector in the short term, while the educational input in Macau had a significant spillover effect on the non educational sector in the short term. The regression results from the formula (IV) show that the education input in Hong Kong has a significant positive spillover effect on non education sectors, while the education input in Macau is not conducive to the long-term output of non education sectors. we can find $\delta$ is the negative number both Hong Kong and Macau, that is, whether it is Hong Kong or Macau, long or short term, the productivity of the education sector is not as good as the non educational sector.

\section{Conclusions and Suggestions}

Conclusions. Through the study of educational investment on economic growth and spillover effects in Hong Kong and Macau, the following conclusions can be draw: First, there is a significant difference in the economic impact of education investment between Hong Kong and Macau. The investment in Hong Kong has a positive impact on the economy for a long time, but there is no 
impact in the short term; the investment in education in Macau has no impact on the long term, but has a positive effect in the short term, and the degree of influence is gradually deepened. This may be due to the early maturity of the education industry in Hong Kong, and the little influence on the short-term economic growth. While the education industry in Macau is at the stage of development, especially in recent years, higher education has developed rapidly and the number of non local students has increased rapidly. Therefore, the increase of educational input will cause more short-term consumption. At the same time, since non local students in Hong Kong can hold temporary Hong Kong identity cards, they can stay in Hong Kong after graduation, supplement and improve the quantity and quality of labor, thus bring long-term economic growth; but non local students in Macau can only hold academic endorsements, and it is difficult to leave Australia after graduation, so it can not bring long-term economic growth. Second, there is a significant difference in the spillover effect of education investment on non education sector between Hong Kong and Macau. In the short term, the education input in Hong Kong has no significant impact on the non educational sector, while the education input in Macau has a significant spillover effect on the non educational sector; in the long run, the input of education in Macau is not conducive to the output of the non educational sector, but the investment in the education sector in Hong Kong has spillover effects. Third, Hong Kong and Macau are not labor intensive areas, and the efficiency of education departments in both places is lower than that of non education sectors. This may be due to the fact that the pillar industries of the non education sector in Hong Kong and Macau are highly profitable industries, such as the financial industry in Hong Kong and the gambling industry in Macau.

Suggestions. This paper suggests that the government of Hong Kong and Macau should not only promote the quality of labor, play the role of talent, and promote economic growth, but also promote the reform of the educational system, optimize the internal management mechanism of the school, improve the teaching level, and then improve the efficiency of the production of the education sector. The government of Macau can draw on Hong Kong's non local student visa policy to enable outstanding non local students to stay in Australia after graduation, to improve the quality of labor and to make up for the shortage of high-end talents. At the same time, in the industrial transformation, Macau can consider the construction of post Degree Research Institute to provide employment opportunities for highly educated talents, and then improve the long-term impact of education input on the economy of Macau.

\section{References}

[1] Schultz, T.W. Investment in Human Capital[J]. American Economic Review, 1961, 51: 1- 17.

[2] Dension E F. The Sources of Economic Growth in the United States and the Alternatives Before US[J]. New York: Committee for Economic Development, 1962.

[3] Romer, P. Increasing Returns and Long Run Growth[J]. Journal of Political Economy, 1986, 94(3): 1002- 1037.

[4] Cai Zengzheng. A quantitative analysis of the contribution of education to economic growth-empirical evidence of the strategy of invigorating the country through science and education [J]. Economic Research, 1999(02):41-50.

[5] Yao Yilong, Liu Jinhua, Xie Mid Autumn Festival. Comparative study on the contribution of education to economic growth: An Empirical Study Based on Feder model and [J]. Academic Research, 2011(12):73-78+160.

[6] ZhongWuya. Educational investment and economic performance-Based on regional comparison between Beijing, Shanghai and Guangdong Province [J].Education and Economy, 2014(02): 64-72.

[7] Xiao Lu, Ming Fan. Educational investment spillover and Jiangsu's economic growth: An Empirical Study [J]. East China economic management, 2008 (09): 10-13. 